\title{
Environmental Education to Promote Peace and Cooperation: A Case Study of Tree Nurseries in Nakuru, Kenya
}

\author{
Emily Zinck \\ Resilience Research Centre \\ Dalhousie University \\ Halifax, Nova Scotia, Canada \\ Carola Eyber \\ Institute of International Health and Development \\ Queen Margaret University \\ Edinburgh, Scotland
}

\begin{abstract}
This field report describes a peace education program in the Nakuru district of Kenya that focuses on environmental education through tree nurseries. The peace clubs introduced tree nurseries as a way of equipping children to take care of their environment. The interaction required to maintain these nurseries strengthens these relationships and promotes cooperation. By planting and caring for tree nurseries, children are able to express their commitment to their community and to the lasting health of their environment.
\end{abstract}

Keywords: peace education, environment, post-conflict, sustainability, Kenya, participation 


\section{Introduction}

The Nakuru district of western Kenya was severely affected by post-election violence in 2008 , which stemmed from a long, re-occurring conflict between members of different ethnic groups in the country as well as deep political divides. Many people were killed and injured, their homes were burnt, and property was stolen (Human Rights Watch 2008; Waki Report 2008). In an effort to prevent violence from erupting again in the future, the National Council of Churches in Kenya (NCCK) introduced "peace clubs" in a group of primary schools in the region.

This field report describes a program in the Nakuru district that works to cultivate a culture of peace by focusing on an environmental awareness activity. Through tree planting, peace club members are encouraged to take care of their environment and to respect their relationship to it. The priority given to children's participation and engagement in these peace club activities is of central importance to the sustainability of this program as well as the positive reception of its messages of peace.

\section{The Nature of Peace Education}

Peace is often understood as simply the absence of or avoidance of violence and conflict. However, in order for sustainable peace to be achievable, it needs to be understood as a "positive presence" instead of merely the absence of violence (Jeong 2005). Ian Harris presents this definition:

Positive Peace is a condition where non-violence, ecological sustainability and social justice remove the causes of violence; requires both the adoption of a set of beliefs by individuals and the presence of social institutions that provide for an equitable distribution of resources and peaceful resolution of conflicts (Harris 2004, 12).

One of the main objectives of peace education as a programmatic intervention is to foster an environment of equality and peace within society through teaching alternatives to violence as well as strategies for peaceful living and cooperation (Harris 2004, 12). Such an intervention has taken many different forms and approaches, allowing it to be culturally relevant in both its content and implementation (Maebuta 2010).

Therefore, any peace education initiative must be appropriate to the local context (Bar-Tal 2002). Peace education can be used to promote children's resilience by "acknowledging and building on their strengths and positive coping strategies" (Ward and Eyber 2009, 19). For example, UNICEF has facilitated programs fostering a culture of peace through various context-specific approaches, such as the Education for Development Project in Mauritius (Fountain 1999) and the Sports Mainstreaming Program in Rwanda (UNICEF 2006).

Environmental issues have become increasingly prominent in both policy and education (Barugh and Gliss 2010). The intersection of the environment and education (Reid 2005) provides a unique opportunity for peace education to incorporate environmental awareness into its message and activities. 


\section{Kenyan Background and Conflict}

Kenya's history has been marred by political and ethnic conflict. The origins of these conflicts are varied and complicated, and relate to a number of factors such as Kenya's colonial history, conflict over resources and the attempt by political leaders to exploit ethnic loyalty, amongst others. The worst of the violence erupted after a disputed federal election which took place on December 27, 2007, between Mwai Kibaki and Raila Odinga. It is this conflict that affected the participants in this report (see Figure 1).

\section{Figure 1. A picture drawn by a student in a peace club, depicting the violence that erupted in the region}

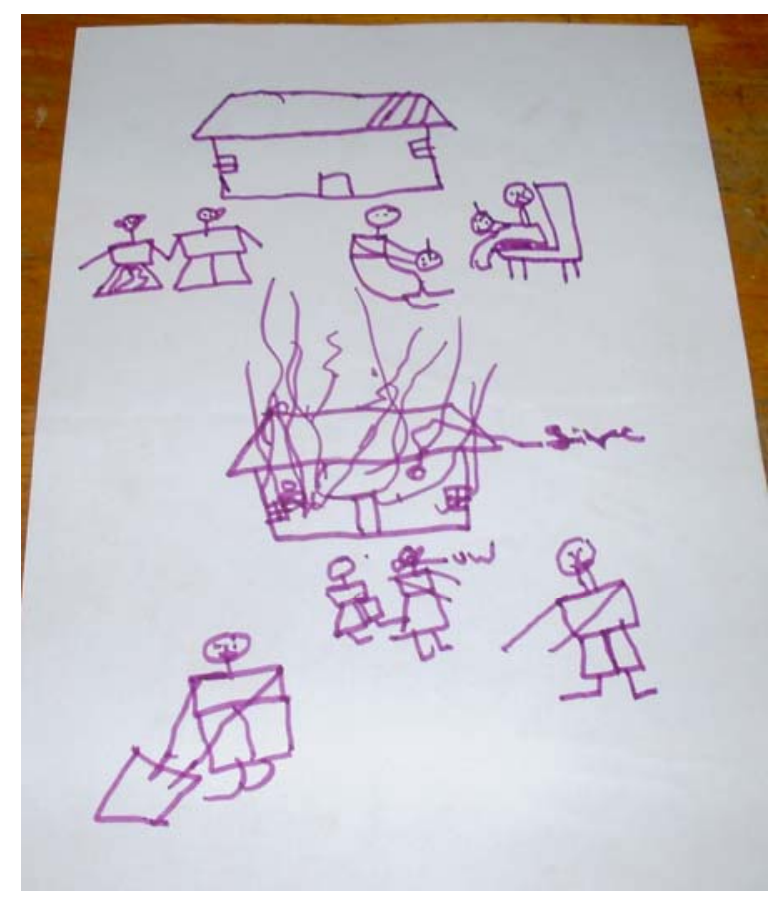

The Nakuru District, located in the south of the Rift Valley province, was heavily affected by the violent conflict, being home to a variety of ethnic groups; the two predominant groups are the Kikuyu and the Kalenjin. More than 1,200 people were killed and some 350,000 displaced into temporary camps, with an equal number seeking refuge with friends or relatives (Human Rights Watch 2008; IRIN 2008). A result of the displacement has been a sharp increase in urban populations, such as the towns of Molo and Nakuru, as there are many who still fear to return home.

The Nakuru District is the most densely populated district in Kenya and suffers from high levels of unemployment and lack of access to basic services such as health care. It is estimated that approximately half of the rural population lives in absolute poverty (NCAPD 2005).

\section{NCCK Peace Clubs}

This research was conducted in collaboration with the National Council of Churches in Kenya (NCCK). The NCCK had been running various peace-building initiatives in 
the community before the violence in 2008 , and participants in this research project were recruited through the NCCK peace club. Three schools, each with its own peace club, were visited by the first author of this report. Each peace club had an average membership of 30 students, with one teacher who led the group. While some of the groups included persons from various ethnic backgrounds, others did not as those schools only had students from one ethnic group. The ages of the children in the peace clubs ranged from 11 to 17 years, with each club having approximately the same number of boys and girls. Students are free to choose to participate in the peace club, and commitment to a club is usually changed or renewed at the beginning of each new academic year. Each peace club meets approximately once a week, often on school property.

The first author conducted a series of semi-structured interviews, led focus group discussions and engaged both the peace club leaders and students in participatory rural appraisal techniques (including drawing activities and ranking exercises). Semi-structured interviews use open-ended questions, allowing the interviewees to elaborate where they wish and to develop on the ideas presented (Ahearn 2000; Denscombe 2007). Similarly, focus groups create a space for open dialogue, giving the researcher a way to observe group interaction (Chambers 1997). Role reversal is the main feature of participatory rural appraisal techniques, where the role of the researcher is to facilitate the activity, while leaving space for the participants to direct the focus. The job for the facilitator is then to "sit back and learn" (Chambers 1997). These methods were chosen for this research because this form of inquiry values the voice and opinions of children involved. This inductive approach to findings emphasizes the complexity of a situation (Creswell 2009), and is well suited to a social constructivist approach to research. The analysis that followed this fieldwork focused largely on identifying themes from both the activities and discussions conducted. These themes were confirmed through the literature surrounding peace education programming and the understanding of how various activities can contribute to a culture of peace.

The aim of this project was to gain insight into the value of peace education in a particular post-conflict setting. The three peace club activities that the children identified as being their favorites were tree planting, football and discussions. In addition, traditional dances, singing and drama are some of the other activities undertaken in some peace clubs. This report will focus mainly on the tree planting activity, as it was discussed at length by both the children and the teachers.

\section{Tree Planting}

As a way of equipping children to take care of their environment, the peace clubs have introduced the idea of tree nurseries. Figure 2 shows two pictures of a tree nursery that was started in 2008 on a school's property. Each of the schools had at least one nursery, varying in size. Peace club members were responsible for all maintenance of the nurseries. This involved planting, weeding, watering, and other general tasks. Children have also been encouraged to begin tree nurseries of their own or with friends. Such projects are not new to Kenya, thanks to the work of Wangari Maathai, the founder of The Green Belt Movement. The idea is not only to further help the environment, but also to give the children a constructive way to 
use their leisure time. Environmental education includes useful concepts of natural resources and global stewardship (Kester 2008), which can be practically applied outside of the school setting.

\section{Figure 2. A tree nursery started and maintained by the students}

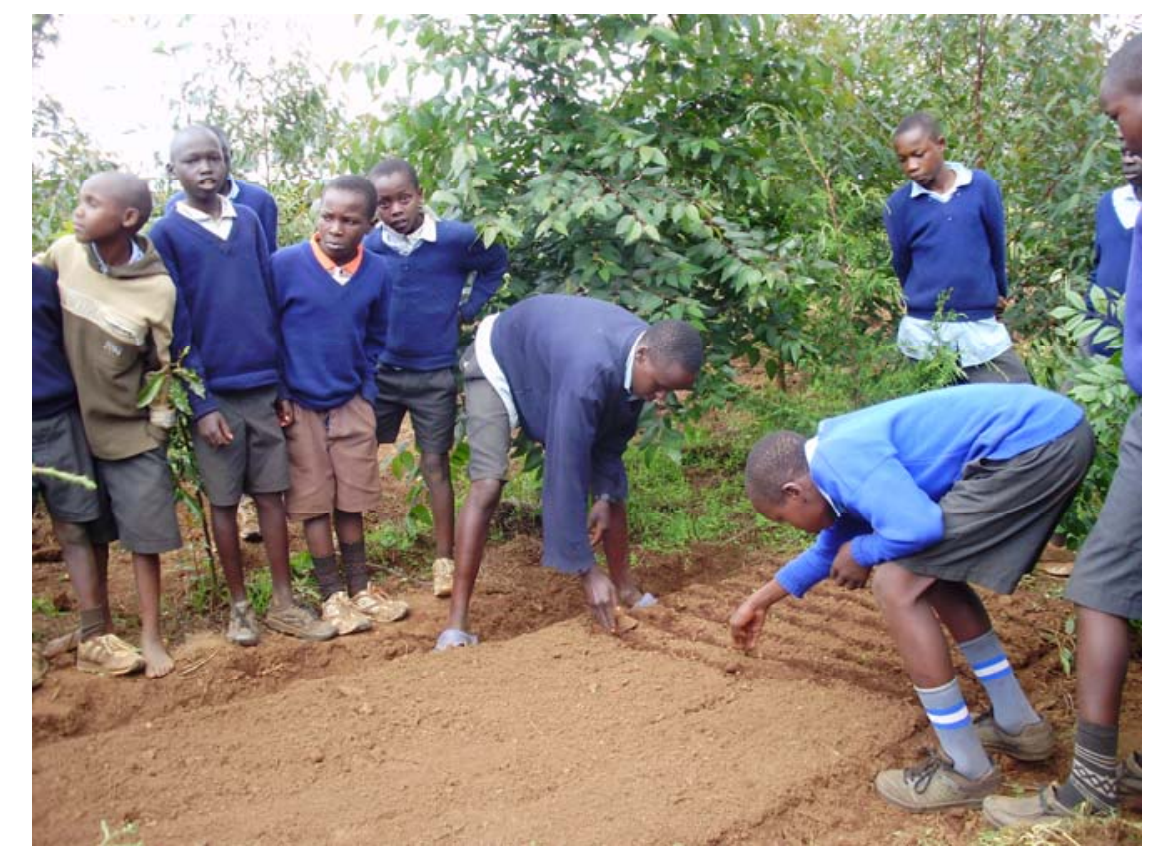

Discussions of the environment have often positioned it as something separate from society; while this is slowly changing, there is still a tendency in the north of the country to consider these as unrelated to one another (Barugh and Gliss 2010). This perspective overlooks the important linkages and influences that each have on the other. An improved understanding of this influence would start by seeing the environment as an intrinsic characteristic of a community, not a peripheral feature. Students involved in tree planting are taught the value of this connection. For example, Anne, age 15, said the following:

Researcher: What about planting trees? How is planting trees important for peace club? Any ideas?

Anne: It brings rain and this helps the country.

Researcher: It brings rain and this helps the country. Ok- can you tell me how does this rain help the country?

Anne: When it rains there will be... many crops and food...

Researcher: And that will bring peace?

Anne: ...it will bring people together from various communities. 
As Anne states, when there is rain there will be enough to eat and people from different communities will be able to come together. The importance here is how the children see their role in promoting peace in their communities. By planting trees, they see peace and cooperation being a regular, long-term part of their communities (see Figure 3).

Figure 3. Drawing of students working together planting trees by J udy, age 12, at Baraka Primary School

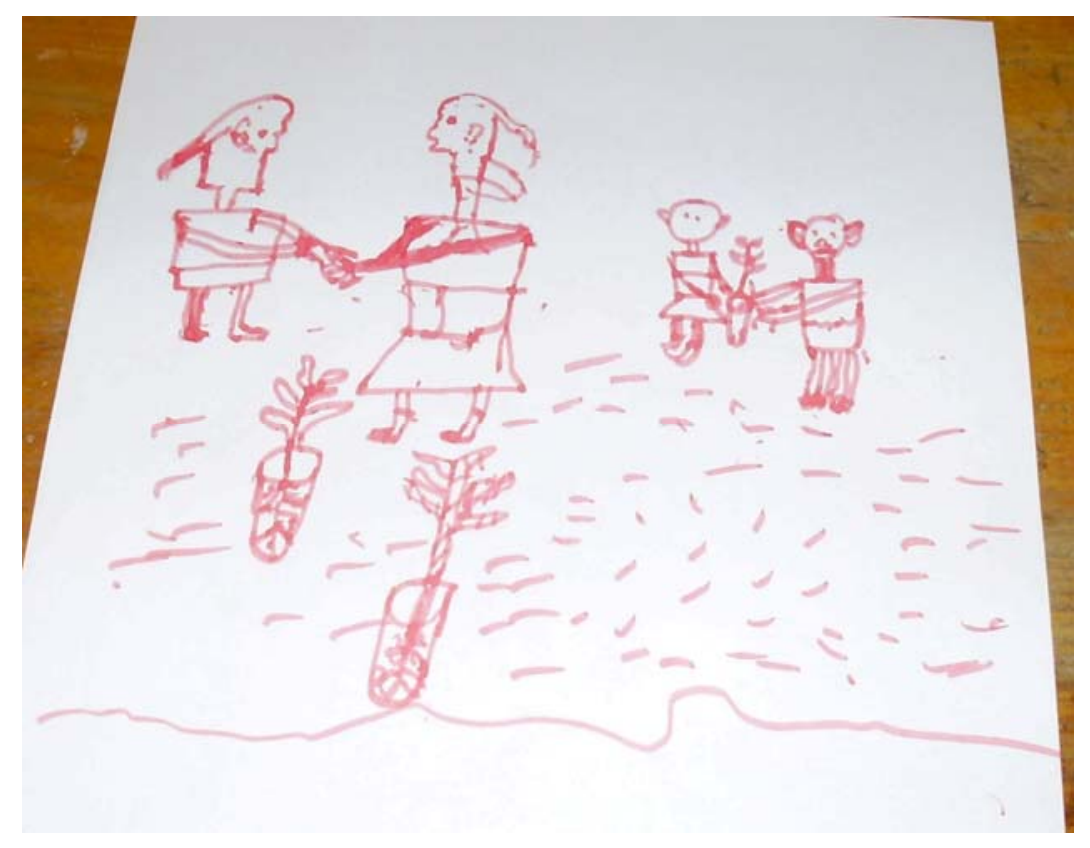

The environment and ecological context have always been areas of focus in discussions of conflict and its causes. During the Cold War, for example, it was acknowledged that the ramifications of a nuclear holocaust would not only affect the human population but also the ecological environment (Harris 2008). In recent years, fears of climate change and global warning have dominated the debates around the environment and its finite resources. In many parts of the world, conflict has been linked to a struggle for control of such resources (e.g., Sierra Leone, Nigeria, and Democratic Republic of Congo), pitting individuals, communities and nations against each other (Theisen 2008).

According to the eco-scarcity theory, there are three types of insufficiencies: environmental, demand-induced and structural (Theisen 2008). This theory links environmental degradation and a shortage of renewable resources directly to conflict, recognizing these as key factors in most unrest around the world (Theisen 2008). It has been suggested that regions of environmental degradation, which usually include high rates of poverty, are prime sites for conflict as people fight for control over the scarce resources that do exist (Stewart 2002). Conflicts such as 
those in Somalia and Rwanda are frequently cited as examples of this causal relationship.

However, this eco-scarcity theory has been criticized of late. Academics such as Ole Magnus Theisen (2008) have argued that focusing on the environment as the sole influence on social harmony neglects other factors such as governmental leadership, insufficient infrastructure, weak economy, and poor social services and support (Theisen 2008). While this is undoubtedly correct, the environment is still a significant factor.

In Kenya, land ownership is of central importance politically, economically and historically, and has been the primary reason for conflict between ethnic groups. It is in this context that peace education programs exist and are seen as a significant factor in building a culture of peace. Clearly, while peace education initiatives do not have the scope to address land distribution at a regional or national level, the use of environmental activities in the peace clubs encourages children to make the most of the environment the communities have, treating it with respect and care. This can be seen as an important dimension of peace education; instilling such attitudes can positively impact a child's personal development as well as foster cooperation and community engagement (see Figure 4). As part of the peace education program, tree planting activities can provide valuable insights into how the environment can not only contribute to violence but, when seen as a collective responsibility, can actually be used to prevent conflict. Tree planting can symbolize this commitment to peace and cooperation.

Figure 4. Drawing by a boy in the peace club at Rafiki Primary School of all the students participating in tree planting

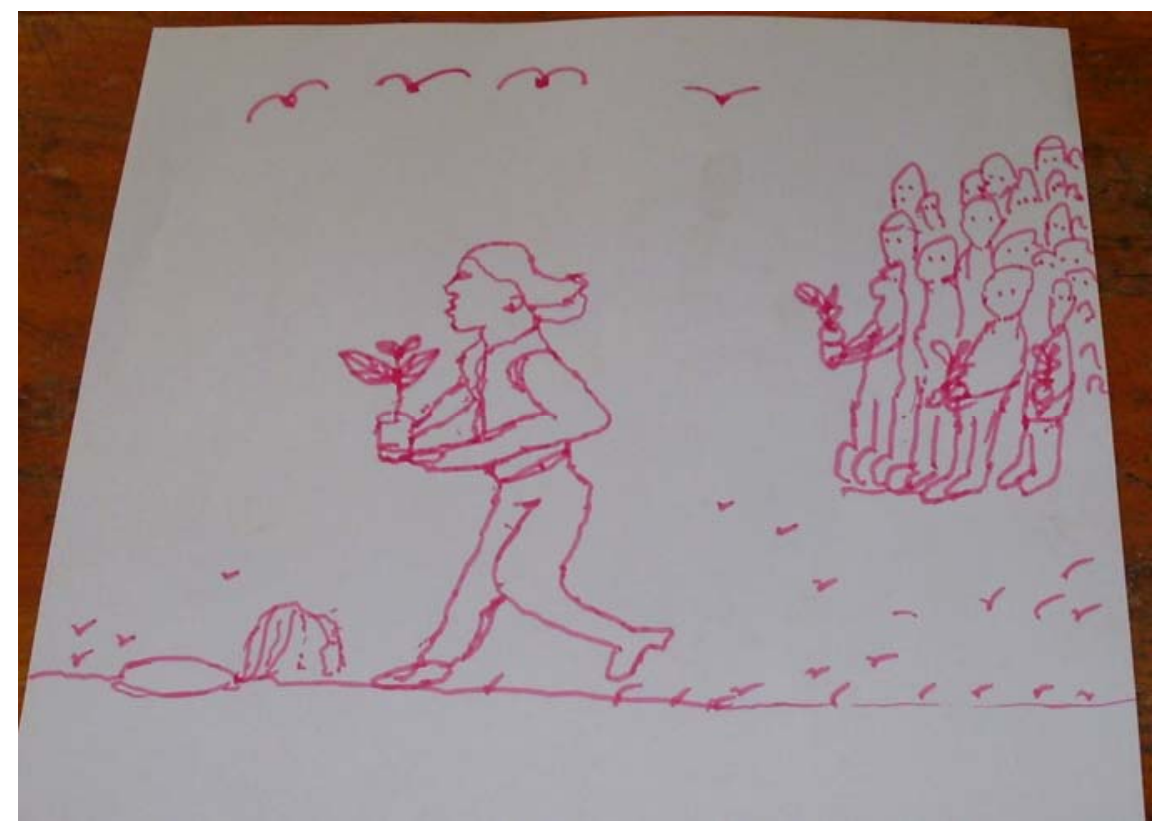




\section{Children's Participation}

So the whole idea of peace clubs was-how do we tell these children... that there is another path of Kenya where there is harmony?... so we began painting to them another picture (Dr. Raphael Kinoti, NCCK, South Rift Region).

By presenting the children with an alternative to violence and conflict, the hope is that children will make the choice to avoid the violence that has come to characterize their communities (Harris and Morrison 2003). What is important to explore is the plausibility of this alternative to violence. The question to ask is not only whether the children are able to achieve that ideal, but also whether they have the necessary resources and tools to do so.

World-wide, increasing emphasis has been placed on children's participation in programs that are intended for their benefit (White and Pettit, 2007). This approach provides a better understanding of children's experiences, and creates opportunities for them to contribute to discussions and interventions that affect their lives (White and Pettit 2007). Better incorporation of children's voices in programming and evaluation can result in more effective and relevant peace education initiatives.

According to Treseder's (1997) depiction of the degrees of children's involvement (Figure 5), the type of participation employed in these peace clubs would fall under "Consulted and Informed." In this category, the students give advice about what programs or projects should be run by the adults, and the adults inform the youth about how their input will be used.

So the few things that we have done they enjoyed because it was them that decided... we let them choose what they want to do (William, peace club volunteer).

This quote demonstrates the importance placed on children's participation in the development of the NCCK peace clubs. The students were consulted during the developing stages of the clubs, and children acknowledged the important role that the environment played in the well-being of their families. By planting trees and caring for tree nurseries, they were able to express their commitment to their community and to the lasting health of their environment. Further, according to the peace club leaders, the activities run in the clubs are informed by what the children want to do, and they are able to give on-going feedback on the various activities. This is a key feature for promoting children's participation in this program. 
Figure 5. Tresder's Approaches to Participation (1997)

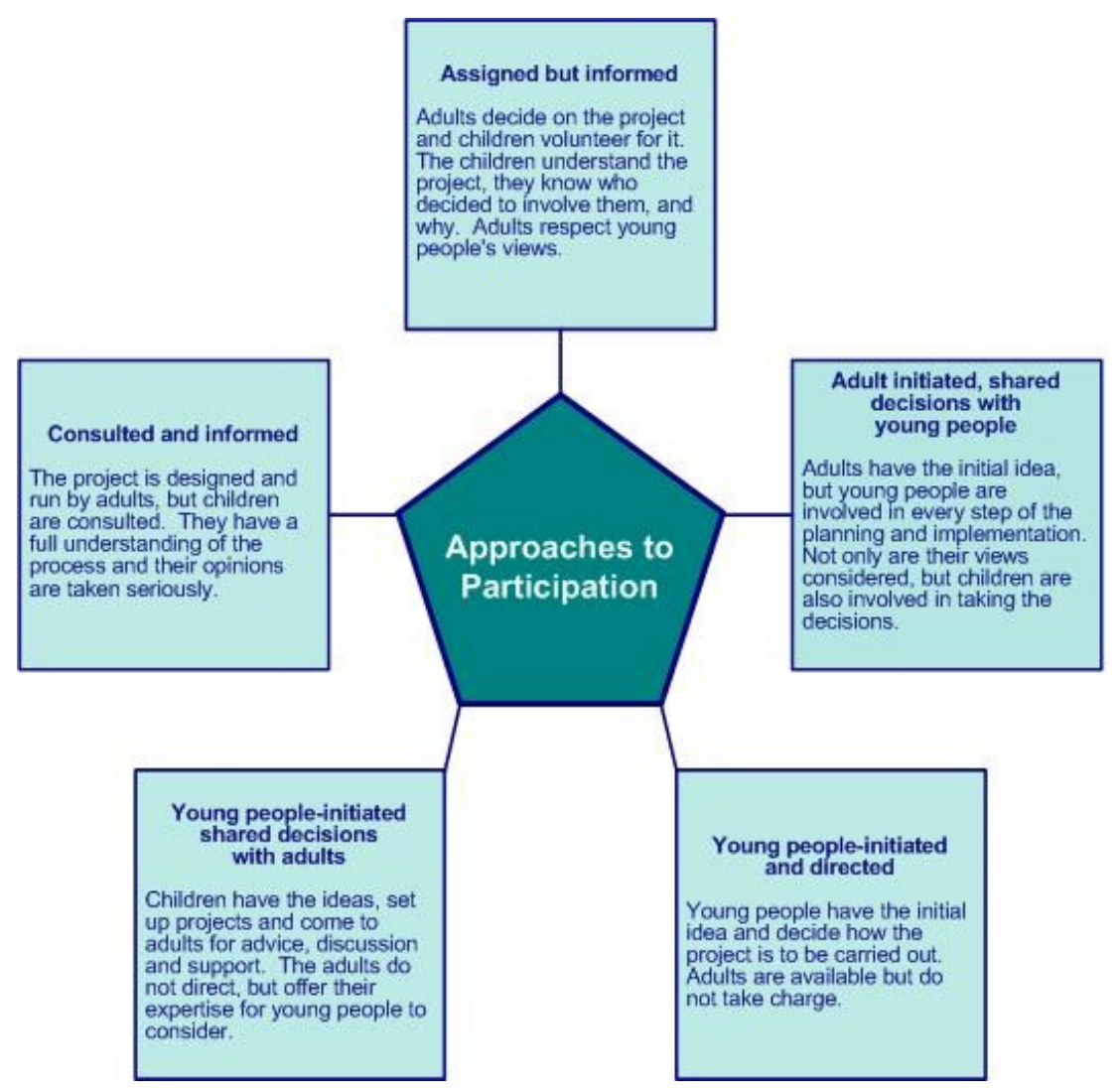

What is interesting to note is that the peace club activities that are the most popular among the children are activities that require the interaction and cooperation of everyone involved. Sports, environmental responsibility and discussion meetings all depend on the club members' commitment to each other and to the common goal of peace. The tree nurseries are a common place, belonging to the students as a group. The interaction required to maintain these nurseries strengthens these relationships and promotes cooperation.

Acknowledging children's resilience and coping strategies is important for understanding and catering for their general health and well-being (Boyden and de Berry 2004). A central mandate of peace education is to develop global citizens, allowing children to see themselves as "peace facilitators," thus acknowledging their agency in shaping and influencing their communities (Harris and Morrison 2003; Hettler and Johnston 2009).

In order to facilitate this empowerment of children, there is a need for a reconfiguration of "adult-child relationships" (Naker, Mann and Rajani 2007, 100). In many contexts, it may be seen as disrespectful to allow children to express themselves in the presence of adults. In Kenya, there is generally a tradition of hierarchical relationships between adults and children (Mburugu and Adams 2004). Therefore, creating space for children in research and program development will 
require careful and context-specific planning. This is not a straightforward undertaking, especially in terms of giving feedback, because they may not feel free to express their opinions without fear of disrespecting their seniors by speaking against them. Alternative channels for communication (e.g., child-friendly spaces, youth councils, and creative means for young people to communicate their ideas) could help to bridge this gap and create a space for children to express their views and concerns freely. Within the peace clubs, the students and club leaders met together to talk about what activities the young people would like to do. Opening up this conversation is an important step in promoting this adult-child collaboration.

More input from children into the peace clubs can benefit the children as well as society. Through individual skill development and self-confidence (Naker, Mann and Rajani 2007), children can be strong advocates of peace, as they often have a strongly developed sense of justice and fairness (Boyden and de Berry 2004). By instilling an awareness of their environment and the role they have in maintaining it, there will be a generational benefit as such convictions will likely be carried on into adulthood.

\section{Conclusions}

The value of a programmatic intervention is measured by those who are primarily intended to benefit from it. By paying more attention to children's voices, peace education can become an even more effective tool in addressing the needs of children and ensuring that the positive effects of peace education will be carried far into the future. It is when these voices are ignored that there is a heightened risk of overlooking a need. Encouraging dialogue about environmental issues and promoting children's involvement is necessary to promote their agency as well as to protect their environment.

It is important to acknowledge what these clubs have accomplished in facilitating positive contact between different ethnic groups after the violence and how effective they have been in working to repair broken relationships. These clubs have been able to bring young people from different ethnicities back together, both through sport and educational activities. How these opportunities will impact the young people's attitudes and behaviors toward future peace efforts remains to be seen. In light of the scarcity of resources for children in the area, peace clubs can give them the opportunity to engage in activities to which they would otherwise not have access. One of the key features of the peace clubs is their openness to the students' input and suggestions for what activities should be done, while paying attention to their needs. This is a strength that we argue is critical for the sustainability and effectiveness of programs with young people.

Peace education has the ability to provide hope for young people-hope that their community or country is aware of the problems it faces and is actively working to achieve something better (Bar-Tal 2002). This kind of hope is essential for moving forward. As environmental concerns continue to plague our world, raising awareness and equipping young people to be agents of change is critical for sustainability. The hope is that this story will spark further discussion about the value of peace education and how it can most effectively be implemented. 


\section{Acknowledgements}

We would like to thank the NCCK for their support for this research project. We are very grateful to Dr. Raphael Kinoti-NCCK Director of the South Rift Region-for all his help and guidance during both the development of this project as well as the first author's time in Nakuru. We are especially thankful for our guide and translator, Dennis, who willingly gave up his time to take us around to the schools and assist in data collection efforts. We would also like to acknowledge Ben Mwarania, Director at Mount Kenya University in Nakuru, for endorsing this project.

Emily Zinck is a Ph.D. candidate in the Interdisciplinary Program at Dalhousie University in Halifax, Canada. Emily is a recent graduate of Queen Margaret University, receiving her MSc with distinction in International Health. Her master's research was an exploratory analysis of a peace education program in the Nakuru District of Kenya. She currently works for the Children and Youth in Challenging Contexts (CYCC) Network as a Research Assistant in the Resilience Research Centre at Dalhousie University, looking at best practice for interventions with at-risk young people.

Dr. Carola Eyber is a lecturer in International Health in the Institute for International Health and Development at Queen Margaret University in Edinburgh, Scotland. Carola is a psychologist whose current interests include children living in challenging environments and the provision of culturally appropriate psychosocial support in situations of forced migration. Currently she is researching policy and practice in relation to children without parental care.

\section{References}

Ahearn, F. (2000). "Psychosocial Wellness: Methodological Approaches to the Study of Refugees." In F. Ahearn, ed. Psychosocial Wellness of Refugees: Issues of Qualitative and Quantitative Research. Oxford: Berghahn, 3-33.

Bar-Tal, D. (2002). "The Elusive Nature of Peace Education." In Solomon, G. and B. Nevo, eds. Peace Education: The Concepts, Principles and Practices in World. New Jersey: Lawrence Erlbaum Inc., 27-36.

Barugh, H. and D. Gliss (2010). “Environment, Climate Change and Popular Education." Concept 1(3): 1-7.

Boyden, J and J. de Berry (2004). Children and Youth on the Front Line: Ethnography, Armed Conflict and Displacement. New York: Berghahn Books.

Chambers, R. (1997). Whose Reality Counts? Putting the First Last. London: IT Publications. 
Creswell, J. (2009). Research Design: Qualitative, Quantitative and Mixed Methods Approaches, $3^{\text {rd }}$ ed. Sage Publications.

Denscombe, M. (2007). The Research Guide: For Small-Scale Social Research Projects, $3^{\text {rd }}$ ed. New York.

Fountain, S. (1999). Peace Education in UNICEF. Working Paper. Education Section- Program Division. New York.

Harris, I. (2004). "Peace Education Theory." J ournal of Peace Education 1(1): 5.

Harris, I. (2008). "History of Peace Education." Encyclopedia of Peace Education. Teachers College, Columbia University. Available from: www.tc. edu/centers/epe/htm\%20articles/Harris_ch2_22feb08.doc.

Harris, I. and M. Morrison (2003). Peace Education, $2^{\text {nd }}$ ed. North Carolina: McFarland \& Co.

Hettler, S. and L. J ohnston (2009). "Living Peace: An Exploration of Experiential Peace Education, Conflict Resolution and Violence Prevention Programs for Youth." Journal of Peace Education 6(1): 101-118.

Human Rights Watch (2008). Ballots to Bullets: Organized Political Violence and Kenya's Crisis of Governance. Report 20: 1(A).

I RI N- Humanitarian News and Analysis (2008). "State Failed to Protect its Citizens During Unrest." Report from UN Office for the Coordination of Humanitarian Affairs. Available from: http://www. irinnews.org/Report. aspx?Reportl d=77360.

J eong, H. (2005). Peace Building in Post-Conflict Societies: Strategies and Process. London: Lynne Rienner Publishers.

Kester, K. (2008). “Developing Peace Education Programs: Beyond Ethnocentrism and Violence Peace Prints." South Asian J ournal of Peace Building 1(1): 1-28.

Maebuta, J . (2010). "Understanding the Indigenous Context for Peace Education in Temotu Nendo, Solomon Islands." Educate 10(1): 2-5.

Mburugu, E.K. and Adams, B.N. (2004). "Families in Kenya." In Adams, B.N. and J. Trost, eds. Handbook of World Families. California: Sage Publications, 3-24.

Naker, D., G. Mann and R. Rajani (2007). "The Gap between Rhetoric and Practice: Critical Perspectives on Children's Participation." Children, Youth and Environments 17(3): 99-103.

Nationals Coordinating Agency for Population and Development (NCAPD) (2005). Nakuru District Plan 2005-2010: For I mplementation of the National 
Population Policy for Sustainable Development. Nairobi, Kenya: Ministry of Planning and National Development.

Reid, B. (2005). "Poverty alleviation and participatory development in the Philippines." Journal of Contemporary Asia 35(1): 29-52.

Stewart, F. (2002). "Root Causes of Violent Conflict in Developing Countries." British Medical J ournal 324: 342-345. Available from:

http: // www. bmj.com/cgi/content/ full/324/7333/342?lookupType=volpage\&vol=324 $\& \mathrm{fp}=342 \&$ view $=$ short.

The Green Belt Movement- Wangari Maathai. Kenya. Available from: http://www. greenbeltmovement. org/wangari-maathai.

Theisen, O.M. (2008). "Blood and Soil? Resource Scarcity and Internal Armed Conflict Revisited." J ournal of Peace Research 45(6): 801-818.

Treseder, P. (1997). Empowering Children and Young People: Promoting Involvement in Decision-Making. Save the Children.

UNI CEF (2006). Sport for Development: Country Examples. Available from: http://www.unicef.org/sports/index_24023.html.

Waki Report (2008). Commission of Inquiry into Post-Election Violence (CIPEV). Available from: http://rescuekenya. wordpress.com/2008/10/20/waki-reportcommission-of-inquiry-into-post-election-violence-cipev/.

Ward, L. and C. Eyber (2009). "Resiliency of Children in Child-Headed Households in Rwanda: Implications for Community-Based Interventions." Intervention 7(1): 17-33.

White, S. and J. Pettit (2007). "Participatory Approaches and the Measurement of Human Well-Being." In McGillivray, M., ed. Human Well-Being: Concept and Measurement. New York: Palgrave Macmillan, 240-268. 